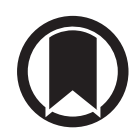

CrossMark

\title{
Absolute values of lung function explain the sex difference in breathlessness in the general population
}

\author{
Magnus Ekström¹, Linus Schiöler², Rune Grønseth ${ }^{3}$, Ane Johannessen ${ }^{4}$, \\ Cecilie Svanes $^{5,6}$, Benedicte Leynaert ${ }^{7}$, Deborah Jarvis ${ }^{8}$, Thorarinn Gislason ${ }^{9,10}$, \\ Pascal Demoly ${ }^{11}$, Nicole Probst-Hensch ${ }^{12}$, Isabelle Pin ${ }^{13,14,15}$, Angelo G. Corsico ${ }^{16}$, \\ Bertil Forsberg ${ }^{17}$, Joachim Heinrich ${ }^{18}$, Dennis Nowak ${ }^{19}$, Chantal Raherison-Semjen ${ }^{20}$, \\ Shyamali C. Dharmage ${ }^{21}$, Giulia Trucco ${ }^{22}$, Isabel Urrutia ${ }^{23}$, \\ Jesús Martinez-Moratalla Rovira ${ }^{24}$, José Luis Sánchez-Ramos (10) ${ }^{25}$, \\ Christer Janson ${ }^{26,27}$ and Kjell Torén ${ }^{2,27}$
}

Affiliations: ${ }^{1}$ Dept of Respiratory Medicine and Allergology, Institution for Clinical Sciences, Lund University, Lund, Sweden. ${ }^{2}$ Section of Occupational and Environmental Medicine, Institute of Medicine, Sahlgrenska Academy, University of Gothenburg, Gothenburg, Sweden. ${ }^{3}$ Dept of Thoracic Medicine, Haukeland University Hospital, Bergen, Norway. ${ }^{4}$ Dept of Global Public Health and Primary Care, University of Bergen, Bergen, Norway. ${ }^{5}$ Centre for International Health, University of Bergen, Bergen, Norway. ${ }^{6}$ Dept of Occupational Medicine, Haukeland University Hospital, Bergen, Norway. ${ }^{7}$ Inserm, UMR 1152, Pathophysiology and Epidemiology of Respiratory Diseases, Paris, France. ${ }^{8}$ Respiratory Epidemiology and Public Health Group, Imperial College London, National Heart and Lung Institute, London, UK. ${ }^{9}$ Dept of Respiratory Medicine and Sleep, Landspitali University Hospital, Reykjavik, Iceland. ${ }^{10}$ Faculty of Medicine, University of Iceland, Reykjavik, Iceland. ${ }^{11}$ Département de Pneumologie et Addictologie, University Hospital of Montpellier, Montpellier, France. ${ }^{12}$ Swiss Tropical and Public Health Institute, University of Basel, Basel, Switzerland. ${ }^{13}$ Pédiatrie, Pôle Couple Enfants, CHU de Grenoble Alpes, Grenoble, France. ${ }^{14}$ INSERM U 1209, Grenoble, France. ${ }^{15}$ Université Grenoble Alpes, Grenoble, France. ${ }^{16}$ Division of Respiratory Diseases, Dept of Internal Medicine and Therapeutics, University of Pavia, Pavia, Italy. ${ }^{17}$ Division of Occupational and Environmental Medicine, Umeå University, Umeå, Sweden. ${ }^{18}$ Helmholtz Zentrum München, German Research Center for Environmental Health, Institute of Epidemiology I, Neuherberg, Germany. ${ }^{19}$ Institute and Outpatient Clinic for Occupational, Social and Environmental Medicine, Inner City Clinic, University Hospital Munich, Ludwig-Maximilians-Universität of Munich, German Center for Lung Research, Munich, Germany. ${ }^{20}$ INSERM U897, Institute of Public Health and Epidemiology, Bordeaux University, Bordeaux, France. ${ }^{21}$ Allergy and Lung Health Unit, School of Population and Global Health, The University of Melbourne, Melbourne, Australia. ${ }^{22}$ Dept of Public Health and Paediatrics, University of Turin, Turin, Italy. ${ }^{23}$ Dept of Respiratory Medicine, Galdakao Hospital, Bizkaia, Spain. ${ }^{24}$ Unit of Pneumology, University Hospital of Albacete, Albacete, Spain. ${ }^{25}$ Dept of Nursing. University of Huelva, Huelva, Spain. ${ }^{26}$ Dept of Medical Sciences, Allergy and Sleep Research, Uppsala University, Uppsala, Sweden. ${ }^{27}$ Both authors contributed equally.

Correspondence: Magnus Ekström, Dept of Medicine, Blekinge Hospital, SE-37185 Karlskrona, Sweden. E-mail: pmekstromagmail.com

@ERSpublications

The sex difference in breathlessness is explained by absolute FEVı or FVC http://ow.ly/TXoI308DZO3

Cite this article as: Ekström M, Schiöler L, Grønseth R, et al. Absolute values of lung function explain the sex difference in breathlessness in the general population. Eur Respir J 2017; 49: 1602047 [https://doi.org/ 10.1183/13993003.02047-2016].

ABSTRACT Activity-related breathlessness is twice as common among females as males in the general population and is associated with adverse health outcomes. We tested whether this sex difference is explained by the lower absolute forced expiratory volume in $1 \mathrm{~s}(\mathrm{FEV} 1)$ or forced vital capacity (FVC) in females.

This was a cross-sectional analysis of 3250 subjects (51\% female) aged 38-67 years across 13 countries in the population-based third European Community Respiratory Health Survey. Activity-related breathlessness was measured using the modified Medical Research Council (mMRC) scale. Associations with mMRC were analysed using ordered logistic regression clustering on centre, adjusting for post-bronchodilator spirometry, body mass index, pack-years smoking, cardiopulmonary diseases, depression and level of exercise.

Activity-related breathlessness (mMRC $\geqslant 1$ ) was twice as common in females $(27 \%)$ as in males $(14 \%)$ (odds ratio (OR) 2.21, 95\% CI 1.79-2.72). The sex difference was not reduced when controlling for FEV 1 $\%$ predicted (OR 2.33), but disappeared when controlling for absolute FEV1 (OR 0.89, 95\% CI 0.69-1.14). Absolute FEV1 explained $98-100 \%$ of the sex difference adjusting for confounders. The effect was similar within males and females, when using FVC instead of FEV1 and in healthy never-smokers.

The markedly more severe activity-related breathlessness among females in the general population is explained by their smaller spirometric lung volumes. 


\section{Introduction}

Breathlessness related to daily activities is common, affecting $15-45 \%$ of middle-aged and older people in the community [1-3]. More severe disability due to activity-related breathlessness measured on the modified Medical Research Council (mMRC) scale [4] is associated with worse health status $[1,5]$ and increased mortality $[6,7]$.

Females report significantly higher prevalence and severity of activity-related breathlessness than males, with odds approximately twice that of males for each level of breathlessness, both in patients with chronic obstructive pulmonary disease (COPD) [8-10] and in the general population [1, 2, 11-13].

The more severe activity-related breathlessness in females is not explained by age, body mass index (BMI), smoking, socioeconomic status, heart disease, chronic airflow limitation (CAL) or lung function impairment $[1-3,9,11,13,14]$. However, recent laboratory data indicate that females have a lower maximal ventilatory capacity and more ventilatory constraints during exercise $[15,16]$. Furthermore, for a given level of physical activity, females have higher respiratory drive, use more of their maximal ventilatory capacity and are more breathless than males [15-17]. The sex disparity was attenuated when controlling for differences in absolute lung volume in the laboratory [15-17] and in patients with severe COPD and emphysema [10]. Taken together, this suggests revisiting the relationship between dyspnoea, sex and lung function.

No population study has evaluated the association between absolute spirometric lung volumes and the sex difference in breathlessness. Most previous studies have included relative lung function, most often forced expiratory volume in $1 \mathrm{~s}$ (FEV1) or forced vital capacity (FVC) expressed as \% predicted when investigating the link between sex and breathlessness $[1-3,9,11,13,14]$. Laboratory studies were small, did not evaluate the interplay of multiple factors or the importance of the suggested mechanisms for breathlessness related to activities of daily life [15-17]. As lower spirometric lung volume might be associated with smoking and increased morbidity, analysis in healthy never-smokers would be informative on a possible causal relationship between lung volumes and activity-related breathlessness.

We aimed to test the hypothesis that the sex difference in activity-related breathlessness is mediated through the lower absolute spirometric lung volume (FEV1 or FVC) in females due to their (on average) smaller lungs, airways and respiratory musculature.

\section{Material and methods}

\section{Study design and population}

This was a cross-sectional analysis of the third multicentre European Community Respiratory Health Survey (ECRHS III). The ECRHS has been detailed elsewhere [18]. ECRHS III was a population-based study of people aged 38-67 years conducted at 27 centres across 12 European countries and Australia between 2010 and 2014 [19]. The present analysis included people in the random population sample with data on the mMRC breathlessness scale $[4,20]$. The exclusion criterion was inability to walk for reasons other than cardiopulmonary disease.

\section{Measurements}

All participants had their height, weight and post-bronchodilator spirometry measured at local study centres and completed written questionnaires on smoking habits, respiratory symptoms, exercise habits and comorbidities.

The outcome severity of activity-related breathlessness was measured using a mMRC scale [20] as breathlessness during strenuous exercise (grade 0), when hurrying on the level or up slight hill (grade 1), when walking on the level (grade 2), when walking for a few minutes (grade 3) and at rest or during minimal activity (grade 4). Grades 3 and 4 were merged due to low numbers.

Post-bronchodilator dynamic spirometry was performed using an EasyOne spirometer (NDD, Andover, MA, USA) by certified technicians according to American Thoracic Society/European Respiratory Society

This article has supplementary material available from erj.ersjournals.com

Received: Oct 202016 | Accepted after revision: Jan 292017

Support statement: The study was supported by unrestricted grants from the Swedish Council for Working Life, Health, and Welfare (FORTE) and Sahlgrenska University Hospital. M. Ekström was supported by unrestricted grants from the Swedish Society of Medicine, the Swedish Respiratory Society, the Swedish Heart-Lung Foundation, the Scientific Committee of Blekinge County Council and the Wera and Emil Cornell Foundation. No funding organisation had a role in the design and conduct of the study, in the analysis and interpretation of data, or in the preparation or approval of the manuscript to be submitted. Funding information for this article has been deposited with the Open Funder Registry.

Conflict of interest: Disclosures can be found alongside this article at erj.ersjournals.com 
standards [21]. Absolute and relative lung volumes were defined as spirometric FEV1 and FVC in litres and \% pred, respectively. Predicted values were estimated using the Global Lung Function Initiative reference values [22]. CAL was defined as $\mathrm{FEV} 1 / \mathrm{FVC}$ below the 5th percentile (lower limit of normal) of the reference population [21]. Exercise was reported as weekly hours of physical activity that led to sweating. Pack-years of smoking was calculated as (mean number of cigarettes per day) $\times$ (years smoking) divided by 20. Occupational exposure was defined as work-related exposure to vapours, gas, dust or fumes. Diagnoses included chronic bronchitis, self-reported asthma, ischaemic heart disease (IHD), hypertension, history of cancer and depression.

\section{Ethical considerations}

Informed consent was obtained from each participant prior to inclusion in ECRHS III. Each study centre obtained approval for the study from their regional committee of medical research ethics according to national legislation.

\section{Statistical analyses}

Stratified analysis and ordered logistic regression were used to explore associations with the mMRC. The variance in mMRC scores explained by sex was measured using McKelveY and Zavoina's [23] $\mathrm{R}^{2}$ as the difference in variance explained by the model with sex compared to the model without sex. The measure of primary interest was the reduction in the variance explained by sex by adding the FEV 1 or FVC to the model as absolute volume and \% pred, respectively.

Potential confounders of the association between lung function and mMRC score for the final model were selected using a directed acyclical graph (DAG) of the relationships between study variables (online supplementary figure S1) [24]. The DAG was based on the literature and input from co-authors [25]. In addition, we evaluated prespecified models adjusting for diseases (asthma, chronic bronchitis, CAL, IHD, history of cancer and depression), risk factors (pack-years of smoking, exercise, occupational exposure, lung infection before the age of 5 years and hypertension) and physiological variables (age, BMI and CAL). The functional form of continuous covariates was investigated using splines. All models accounted for clustering within countries using robust variance estimation [26]. The analysis included complete cases only. No data were imputed. Associations were expressed as odds ratios (OR) with 95\% confidence intervals. For each level of mMRC, an OR of 2.0 for sex is interpreted as the odds of having a higher mMRC score being twice as high in females as in males. The proportional odds assumption of ordinal logistic regression was evaluated by repeating the analyses using a partial proportional odds model, with similar findings. Findings were similar when analysing mMRC dichotomously ( $\geqslant 1$ versus 0$)$ using logistic regression.

Analyses were performed in the total study population, females and males separately and in healthy never-smokers, defined as never-smokers without CAL, self-reported chronic bronchitis, IHD, history of cancer or depression. Statistical analyses were performed using Stata (version 12.1; StataCorp, College Station, TX, USA).

\section{Results}

Participants

3250 participants (51\% female) were included in the analysis. Included and excluded patients had similar characteristics (online supplementary table S1). The mean \pm SD age of included participants was $54 \pm 7.0$ years (table 1). Compared with males, females had lower mean absolute FEV1 (2.7 versus $3.7 \mathrm{~L}$ ), but similar $\mathrm{FEV}_{1} \%$ pred, slightly lower BMI and less smoking exposure, but more asthma and prior depression (table 1).

\section{Sex difference of breathlessness}

Activity-related breathlessness $(\mathrm{mMRC} \geqslant 1)$ was twice as common in females $(27 \%)$ as in males $(14 \%$; table 1) (unadjusted OR 2.21, 95\% CI 1.79-2.72) for more severe breathlessness. The sex difference was not reduced when controlling for age, BMI, chronic bronchitis, CAL, pack-years of smoking, exercise, IHD and a history of depression (OR 2.63, 95\% CI 2.12-3.25) in the final model (table 2).

\section{Predictors of breathlessness}

In the final model, independent predictors of increased activity-related breathlessness were lower FEV 1 (absolute or relative value), higher BMI, less exercise, chronic bronchitis (strong association), IHD and history of depression (table 3). Smoking and CAL predicted breathlessness only when not adjusting for absolute FEV1. The estimates for predictors were similar in males and females, except that females had weaker associations for exercise and IHD, and stronger associations for chronic bronchitis (table 3). 
TABLE 1 Characteristics of 3250 subjects from the general population

\begin{tabular}{|c|c|c|c|}
\hline & Females & Males & All \\
\hline Subjects & $1673(51)$ & 1577 (49) & 3250 \\
\hline Age years & $53.7 \pm 7.0$ & $54.2 \pm 7.0$ & $54.0 \pm 7.0$ \\
\hline \multicolumn{4}{|l|}{ mMRC breathlessness score } \\
\hline 0 & $1226(73)$ & $1349(86)$ & 2575 (79) \\
\hline 1 & $343(21)$ & 203 (13) & $546(17)$ \\
\hline 2 & $95(6)$ & $22(1)$ & $117(4)$ \\
\hline $3-4$ & $9(1)$ & $3(0)$ & $12(0)$ \\
\hline FEV 1 L & $2.67 \pm 0.46$ & $3.68 \pm 0.66$ & $3.16 \pm 0.76$ \\
\hline FEV1 \% predicted & $98.8 \pm 13.8$ & $98.5 \pm 14.5$ & $98.7 \pm 14.1$ \\
\hline FVC L & $3.39 \pm 0.56$ & $4.74 \pm 0.80$ & $4.04 \pm 0.96$ \\
\hline FVC $\%$ predicted & $99.6 \pm 12.9$ & $99.2 \pm 13.5$ & $99.4 \pm 13.2$ \\
\hline FEV $1 / F V C$ & $0.79 \pm 0.06$ & $0.78 \pm 0.06$ & $0.78 \pm 0.06$ \\
\hline$B M I \mathrm{~kg} \cdot \mathrm{m}^{-2}$ & $26.3 \pm 5.0$ & $27.2 \pm 4.1$ & $26.7 \pm 4.6$ \\
\hline$<18.5$ & $18(1)$ & $5(0)$ & $23(1)$ \\
\hline $18.5-<25$ & $770(46)$ & $480(30)$ & 1250 (38) \\
\hline $25-30$ & 554 (33) & 775 (49) & $1329(41)$ \\
\hline$>30$ & $331(20)$ & $317(20)$ & $648(20)$ \\
\hline \multicolumn{4}{|l|}{ Smoking } \\
\hline Pack-years & $1.3(0-19.2)$ & $7.0(0-30.5)$ & $3.9(0-24.3)$ \\
\hline Current smoker & $283(17)$ & $398(19)$ & $581(18)$ \\
\hline Never-smoker & $801(48)$ & $645(41)$ & $1446(44)$ \\
\hline Occupational exposure & $569(34)$ & $947(60)$ & $1516(40)$ \\
\hline \multicolumn{4}{|l|}{ Exercise $h \cdot$ week $^{-1}$} \\
\hline$\geqslant 2$ & $688(41)$ & $763(48)$ & $1451(45)$ \\
\hline $0.5-1$ & $437(26)$ & $366(23)$ & $803(25)$ \\
\hline None & $548(33)$ & $448(28)$ & $996(31)$ \\
\hline Asthma & $248(15)$ & $171(11)$ & $419(13)$ \\
\hline CAL FEV $1 / F V C<L L N$ & $73(4)$ & $87(6)$ & $160(5)$ \\
\hline Chronic bronchitis & $148(9)$ & $160(10)$ & $308(9)$ \\
\hline IHD & $24(1)$ & $45(3)$ & $69(2)$ \\
\hline Severe respiratory infection aged $<5$ years & $168(10)$ & $146(9)$ & $314(10)$ \\
\hline History of cancer & $95(6)$ & $82(5)$ & $177(5)$ \\
\hline History of depression & $301(18)$ & $168(11)$ & $469(14)$ \\
\hline
\end{tabular}

Data are presented as $\mathrm{n}(\%)$, mean \pm SD or median (interquartile range). Percentages may not sum to 100 , due to rounding. mMRC: modified Medical Research Council; FEV1: post-bronchodilatory forced expiratory volume in $1 \mathrm{~s}$; FVC: post-bronchodilatory forced vital capacity; BMI: body mass index; CAL: chronic airflow limitation; LLN: lower limit of normal; IHD: ischaemic heart disease.

Both a lower absolute and relative FEV1 were associated with more severe activity-related breathlessness (online supplementary figure S2). As shown in figure 1, the associations remained when adjusting for possible confounders and were similar in males and females (table 2) for both the absolute FEV1 $(p=0.69$ for interaction) and \% pred ( $\mathrm{p}=0.49$ for interaction).

\section{Spirometric lung volume and sex difference in breathlessness}

Adjusting for FEV1 \% pred did not reduce the sex difference in activity-related breathlessness (OR 2.66, 95\% CI 2.13-3.34). In contrast, the sex difference disappeared when adjusting for absolute FEV1 (OR 0.89, 95\% CI 0.69-1.14). This was consistent with stratified analysis (online supplementary table S2). Differences in absolute FEV1 explained $98-100 \%$ of the difference (variance) in activity-related breathlessness between males and females (figure 2), which was consistent when controlling for age, BMI, smoking, exercise level, diseases and other risk factors (table 3). Findings were similar when analysing FVC instead of FEV1 (online supplementary figure S3 and table S3), which is also shown in figure 2.

The absolute FEV1 was closely correlated to height $(\mathrm{r}=0.72)$. In a sensitivity analysis adding height to the final model, the association for FEV1 remained unchanged (OR 0.42 versus OR 0.48 in table 3 ) but the association for height became nonsignificant (OR 1.02, 95\% CI 1.00-1.04; $\mathrm{p}=0.065$ ). Compared with height, absolute FEV1 was a stronger predictor and explained more of the sex difference in breathlessness (98\% versus 55\%). Findings were consistent when including weight instead of BMI and when not adjusting for level of exercise in the final model. 
Healthy never-smokers

Findings were consistent in healthy never-smokers ( $\mathrm{n}=971$ (30\%); 455 males and 516 females). The more severe adjusted activity-related breathlessness in females (OR 2.69, 95\% CI 1.94-3.73) was not reduced by FEV1 \% pred (OR 2.71, 95\% CI 1.96-3.76), but by absolute FEV1 (OR 1.65, 95\% CI 1.07-2.53; p=0.039 for change). The absolute FEV 1 explained $96 \%$ of the sex difference in activity-related breathlessness among healthy never-smokers.

\section{Discussion}

Main findings

In a middle-aged general population, we found the following. 1) Females reported approximately twice as much activity-related breathlessness as males; 2) the sex difference was eliminated when accounting for the absolute FEV1 or FVC, whereas it was not reduced when controlling for the level of lung function impairment (\% pred); and 3) the association between lower spirometric lung volumes and increased breathlessness was similar across males and females and in healthy never-smokers.

\section{Sex difference in activity-related breathlessness}

The finding of increased activity-related breathlessness in females is in line with previous population-based studies [1-3, 14], including one from five Latin American cities [1] and the Burden of Obstructive Lung Disease (BOLD) study of 15 countries, and thus seems to have high validity globally $[2,11]$.

The sex disparity increased from OR 2.21 to 2.63 when controlling for potential confounders, which was also seen in the BOLD study [2]. This probably reflects that several determinants of more severe breathlessness, such as overweight and IHD were less common in females than males. No factor except absolute spirometric lung volumes was found to decrease the sex difference in the final model, which was unchanged in previous studies adjusting for education level and socioeconomic status $[2,3,14]$.

That absolute FEV1 and FVC explained the sex difference in activity-related breathlessness is consistent with a study of selected patients with severe emphysema [10]. The effect of absolute spirometric lung volume was robust across models controlling for potential confounders.

The impact of absolute spirometric lung volume was not mainly related to sex differences in body size. Although height and absolute FEV1 were closely correlated, height explained less of the sex difference (55\% versus $98 \%$ ) and did not predict breathlessness independent of the absolute FEV1.

The association between lower spirometric lung volumes and increased breathlessness was not explained by concurrent lung volume impairment, as most participants had normal lung function and findings were similar in healthy never-smokers.

\section{Mechanisms}

The present findings are consistent with recent laboratory data that females have smaller absolute lung volumes and experience more dyspnoea for a given absolute work rate, ventilation or metabolic requirement during laboratory-based cardiopulmonary exercise testing in young and older subjects [15-17, 27]. In addition to having smaller lungs, females have narrower airways than males, even when matched on lung size (dysanapsis) [12, 28, 29]. Narrower airways could contribute to the increased exertional breathlessness in females, probably at least partly mediated through reduced ventilatory capacity [30]. In the laboratory, the sex difference in breathlessness disappears when ventilation is expressed as a percentage of maximal voluntary ventilation or when accounting for the reduced exercise capacity in females [15-17, 27]. In other words, females breathe at a higher percentage of their ventilatory capacity, resulting in increased resistive work of breathing and increased neural ventilatory drive [31] for any given work rate or minute ventilation, and therefore experience more breathlessness $[17,32]$.

\section{Implications}

This study extends previous laboratory data and supports that absolute spirometric lung volume has an important impact on the severity of breathlessness related to daily activities, and that it explains the difference in severity between males and females in the general population. This highlights the importance of evaluating both the relative and the absolute lung volume in research and clinical practice. By just focusing on the relative values we may miss associations of which the causal pathway includes the absolute lung volume. Relative lung volume reflects the level of lung volume impairment compared to the predicted normal value, and might reflect an active disease process (such as COPD) that influences the trajectory of absolute lung volume over time, as well as systemic consequences of the disease, health status and mortality [33]. However, the functional impact of a given impairment depends on the person's baseline absolute lung volume, which reflects the remaining ventilatory capacity. Importantly, smaller absolute spirometric lung volume was associated with more severe activity-related breathlessness both overall and 
TABLE 2 Absolute forced expiratory volume in $1 \mathrm{~s}$ (FEV1) and sex-related difference in breathlessness

$\begin{array}{cc}\text { Females versus } & \begin{array}{c}\text { Variance } \\ \text { males OR }(95 \% \mathrm{CI})\end{array} \\ \text { explained by sex }\end{array}$

Females versus
males OR $(95 \% \mathrm{Cl})$

$0.89(0.69-1.14)$

$1.18(0.88-1.59)$

$0.99(0.78-1.26)$

$1.13(0.79-1.61)$

$2.28(1.90-2.77)$

$2.56(2.07-3.16)$

Physiology

$2.63(2.12-3.25)$

\begin{tabular}{ll}
\hline Crude & $2.21(1.79-2.72)$ \\
Risk factors & $2.52(2.01-3.11)$ \\
Diseases & $2.28(1.90-2.77)$ \\
Physiology & $2.56(2.07-3.16)$ \\
Final & $2.63(2.12-3.25)$
\end{tabular}

Sex difference in breathlessness expressed as odds ratios (OR) of more severe breathlessness for females compared with males in models with or without the absolute value of $\mathrm{FEV}_{1}(\mathrm{n}=3250)$. The sex estimates were crude and adjusted for risk factors (pack-years of smoking, exercise, occupational exposure, lung infection at age $<5$ years and hypertension); diseases (asthma, chronic bronchitis, chronic airflow limitation (CAL), ischaemic heart disease (IHD) and history of cancer or depression); and physiology lage, body mass index (BMI) and CAL). The final model was controlled for age, BMI, chronic bronchitis, CAL, pack-years smoking, exercise, IHD and history of depression. Analysis performed using ordinal logistic regression clustering on country with 3250 participants in all models. The variance in modified Medical Research Council scores explained by sex was measured as the difference in variance explained by the model with sex compared to the model without sex, using McKelveY and ZavoInA's $R^{2}$ [23].

within each sex; males with smaller lungs had more severe breathlessness than males with larger lungs, with the same seen among females.

Among females in the present study, a FEV1 of $50 \%$ pred corresponds to an average FEV1 of $1.34 \mathrm{~L}$, whereas the mean FEV1 in males with the same level of lung function impairment is $1.84 \mathrm{~L}$, a difference of $500 \mathrm{~mL}$ or $37 \%$ higher compared with females. Although matched on relative lung volume, males and females can therefore have markedly different absolute lung volume or ventilatory capacity, which may explain the sex disparity in breathlessness seen in previous clinical studies matching on the FEV1\% pred [8-11]. An important implication for future clinical studies is that matching on relative lung volume puts females at a disadvantage in relation to breathlessness due to their average lower absolute lung volume. This sex bias can be overcome by accounting for absolute lung volume.

Clinically and in studies, absolute lung volumes are rarely analysed or reported and its importance in breathlessness has been largely overlooked. We propose that in both research and clinical care, relative and absolute spirometric lung volumes provide complimentary information on the lung volume impairment and remaining ventilatory reserve.

TABLE 3 Final model of absolute forced expiratory volume in $1 \mathrm{~s}$ (FEV1) and sex difference in breathlessness in 3250 subjects from the general population

\begin{tabular}{|c|c|c|c|}
\hline & Overall & Females & Males \\
\hline Subjects $\mathrm{n}$ & 3250 & 1673 & 1577 \\
\hline Females versus males & $1.29(0.89-1.87)$ & & \\
\hline FEV1 per L & $0.48(0.33-0.69)$ & $0.48(0.33-0.69)$ & $0.48(0.30-0.75)$ \\
\hline Age per year & $0.99(0.97-1.01)$ & $0.99(0.98-1.01)$ & $0.98(0.95-1.02)$ \\
\hline BMI per $\mathrm{kg} \cdot \mathrm{m}^{-2}$ & $1.10(1.07-1.13)$ & $1.10(1.07-1.13)$ & $1.11(1.06-1.16)$ \\
\hline Exercise $\geqslant 2 \mathrm{~h} \cdot$ week $^{-1}$ & Ref. & Ref. & Ref. \\
\hline Exercise $0.5-1 \mathrm{~h} \cdot$ week $^{-1}$ & $1.53(1.20-1.96)$ & $1.24(0.92-1.69)$ & $2.31(1.71-3.11)$ \\
\hline No exercise & $2.17(1.66-2.84)$ & $1.77(1.25-2.50)$ & $3.16(2.20-4.55)$ \\
\hline Smoking per pack-year ${ }^{\#}$ & $1.00(1.00-1.01)$ & $1.00(0.99-1.01)$ & $1.01(1.00-1.01)$ \\
\hline CAL FEV $1 / F V C<L L N$ & $1.40(0.83-2.37)$ & $1.44(0.87-2.36)$ & $1.33(0.63-2.82)$ \\
\hline Chronic bronchitis & $2.22(1.71-2.89)$ & $2.68(1.94-3.70)$ & $1.65(1.02-2.68)$ \\
\hline IHD & $1.60(1.01-2.52)$ & $1.34(0.67-2.69)$ & $2.01(1.13-3.56)$ \\
\hline History of depression & $1.37(1.10-1.71)$ & $1.53(1.17-2.00)$ & $1.03(0.64-1.66)$ \\
\hline
\end{tabular}

Data are presented as odds ratio $(95 \% \mathrm{Cl})$, unless otherwise stated. Adjusted associations with the severity of exercise-related breathlessness on the modified Medical Research Council dyspnoea (mMRC) scale overall and in males and females separately, estimated using ordered logistic regression clustering over 24 centres. The model explained $22.8 \%$ of the variation in $\mathrm{mMRC}$ scores. $\mathrm{FEV} 1$ : forced expiratory volume in $1 \mathrm{~s}$; $\mathrm{BMI}$ : body mass index; CAL: chronic airflow limitation; FVC: forced vital capacity; LLN: lower limit of normal; IHD: ischaemic heart disease; ref.: reference. ${ }^{\#}$ : (mean cigarettes per day/20) $\times$ (number of years of smoking). 


\section{Strengths and limitations}

This was an international, multicentre study that included a large general population sample with standardised assessments across 13 countries [21]. The analyses accounted for variability between study centres and potential confounders including BMI, detailed smoking exposure and the presence of cardiopulmonary disease and risk factors. Sensitivity analyses showed consistent results supporting the validity of the findings. Both FEV1 and FVC were analysed, as they may contribute complimentary information on airway size and respiratory mechanics which influence exertional breathlessness.

Some potential limitations deserve mentioning. First, we excluded subjects with missing study data. However, the representativeness of the sample for the general population is supported in that their characteristics were similar to those of the excluded people and were similar to in previous population-based studies [1,2]. A previous analysis found no major effect of missing data in ECRHS on analyses of symptoms [34]. The findings pertain to subjects aged 38-67 years. Second, we lacked data on standardised exercise tests. Exercise tests have limited feasibility in large population-based studies. The mMRC is a discriminative and valid measure that performs similar to other instruments of activity-related breathlessness $[4,35,36]$. It is strongly related to health status $[1,4,5]$ and mortality $[6,7]$, and is commonly used, enabling comparisons between studies $[1,2,4]$. Finally, we have not measured static lung volumes, diffusion capacity or cardiopulmonary exercise capacity, which should be evaluated to provide more detailed information concerning both the nature and implication of reduced spirometric lung volumes.

\section{Relationship to prevailing hypotheses}

This study does not support the prevailing view that females report more activity-related breathlessness for a given lung function impairment compared to males mainly because of hormonal, affective or sociocultural reasons $[11,12,37,38]$. Breathlessness is a complex experience that consists of qualitatively distinct sensations that arise through interplay of biochemical, mechanical, neurobiological, affective and sociocultural factors [35]. This is reflected in our final model, where only $22.8 \%$ of the mMRC variance was explained in the population. However, accounting for differences in absolute lung volume eliminated the difference in activity-related breathlessness between males and females. Females have been found to select more unpleasant descriptors of breathlessness at peak exercise, which might be due to females breathing closer to their maximum ventilatory capacity [27]. In the same study, the intensity of breathlessness was similar in males and females when expressing ventilation as a percentage of the individual's maximum ventilation [27]. The importance of the ventilatory capacity rather than sex for exertional breathlessness is supported by laboratory findings that males and females experience a similar increase in the intensity and unpleasantness of breathlessness for a similar change in ventilatory motor drive [16].

\section{New hypothesis}

The present findings support that the functional impact of a given lung volume impairment depends on the underlying absolute lung volume $[11,39]$. We further hypothesise that people with smaller absolute lung volumes are at increased risk of developing significant activity-related breathlessness in relation to different disease processes or noxious exposures such as smoking, which needs to be validated in longitudinal studies.
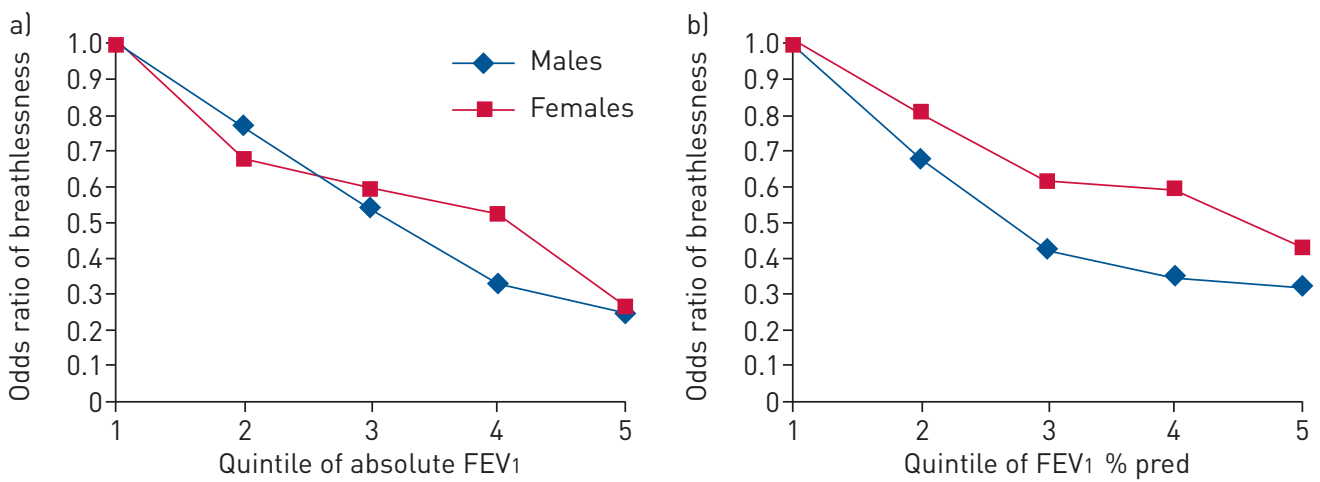

FIGURE 1 Adjusted association between absolute and relative forced expiratory volume in $1 \mathrm{~s}\left(\mathrm{FEV}_{1}\right)$ and activity-related breathlessness. Lower FEV1 was associated with more severe activity-related breathlessness in the general population $(n=3250)$ for a) the absolute $F E V_{1}$ and $b$ ) the relative $F E V_{1} \%$ predicted. Higher quintiles of FEV1 imply higher FEV1 values. Odds ratios are compared with the lowest quintile of FEV1 (quintile 1), and are adjusted for age, body mass index, hours of exercise per week, pack-years of smoking, chronic bronchitis, chronic airflow limitation, ischaemic heart disease and history of depression. The adjusted association with modified Medical Research Council scores was similar between males and females both for absolute $\mathrm{FEV}_{1}$ ( $\mathrm{p}=0.69$ for interaction) and $\mathrm{FEV}_{1} \%$ pred ( $\mathrm{p}=0.49$ for interaction). 


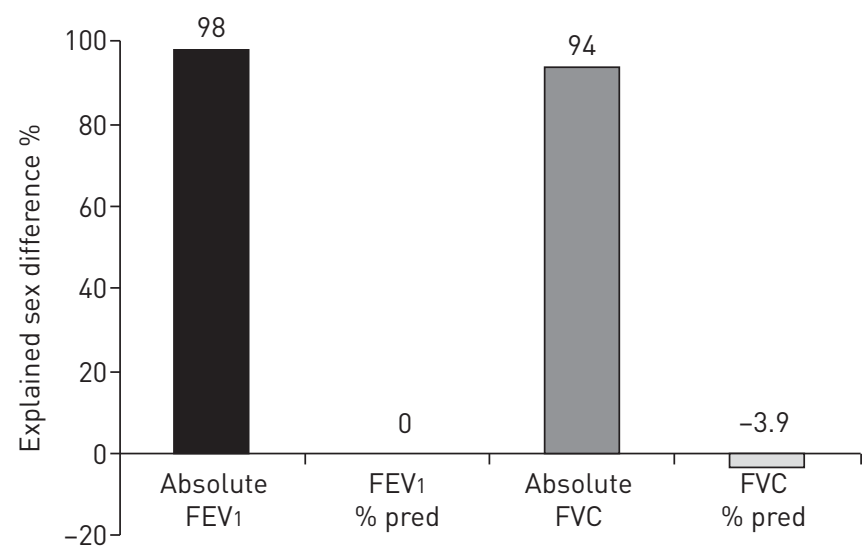

FIGURE 2 Percentage of the sex difference in activity-related breathlessness explained by forced expiratory volume in $1 \mathrm{~s}$ (FEV1) and forced vital capacity (FVC) expressed in absolute volume and \% predicted in the general population ( $n=3250$ ). Sex difference was measured as the variance in the modified Medical Research Council breathlessness score explained by sex in ordinal logistic regression adjusted for age, body mass index, chronic bronchitis, chronic airflow limitation, pack-years smoking, exercise, ischaemic heart disease and a history of depression. The sex disparity disappeared when adjusting for differences in the absolute FEV 1 or FVC between males and females. In contrast, the sex difference was not reduced when adjusting for FEV1 or FVC in \% pred.

\section{Conclusion}

The markedly more severe activity-related breathlessness in females was explained by differences in absolute FEV1 or FVC in the general population. The association between lower lung volumes and increased breathlessness was similar in males and females and among healthy never-smokers. This highlights the importance of both relative and absolute values of lung function to evaluate the level of lung impairment and remaining ventilatory reserve.

\section{Acknowledgements}

We thank Thomas Åkesson (Dept of Clinical Physiology, Växjö Hospital, Växjö, Sweden) for valuable discussions and feedback. Authors' contributions: M. Ekström was the guarantor of the study and all authors had full access to all of the data in the study and take full responsibility for the integrity of the data and the accuracy of the data analysis. Conception: M. Ekström; design: A. Johannessen, L. Schiöler, M. Ekström and R. Grønseth; acquisition of data: all authors; analysis: L. Schiöler and M. Ekström; interpretation of data: A. Johannessen, B. Leynaert, C. Janson, C. Svanes, K. Torén, L. Schiöler, M. Ekström and R. Grønseth; drafting the article: A. Johannessen, L. Schiöler, M. Ekström and R. Grønseth; revision for important intellectual content and approval of the version to be published: all authors.

\section{References}

1 Lopez Varela MV, Montes de Oca M, Halbert RJ, et al. Sex-related differences in COPD in five Latin American cities: the PLATINO study. Eur Respir J 2010; 36: 1034-1041.

2 Grønseth R, Vollmer WM, Hardie JA, et al. Predictors of dyspnoea prevalence: results from the BOLD study. Eur Respir J 2014; 43: 1610-1620.

3 Bowden JA, To TH, Abernethy AP, et al. Predictors of chronic breathlessness: a large population study. BMC Public Health 2011; 11: 33.

4 Bestall JC, Paul EA, Garrod R, et al. Usefulness of the Medical Research Council (MRC) dyspnoea scale as a measure of disability in patients with chronic obstructive pulmonary disease. Thorax 1999; 54: 581-586.

5 Jones PW, Adamek L, Nadeau G, et al. Comparisons of health status scores with MRC grades in COPD: implications for the GOLD 2011 classification. Eur Respir J 2013; 42: 647-654.

6 Figarska SM, Boezen HM, Vonk JM. Dyspnea severity, changes in dyspnea status and mortality in the general population: the Vlagtwedde/Vlaardingen study. Eur J Epidemiol 2012; 27: 867-876.

7 Nishimura K, Izumi T, Tsukino M, et al. Dyspnea is a better predictor of 5-year survival than airway obstruction in patients with COPD. Chest 2002; 121: 1434-1440.

8 de Torres JP, Casanova C, Hernández C, et al. Gender and COPD in patients attending a pulmonary clinic. Chest 2005; 128: 2012-2016.

9 de Torres JP, Casanova C, Montejo de Garcini A, et al. Gender and respiratory factors associated with dyspnea in chronic obstructive pulmonary disease. Respir Res 2007; 8: 18.

10 Martinez FJ, Curtis JL, Sciurba F, et al. Sex differences in severe pulmonary emphysema. Am J Respir Crit Care Med 2007; 176: 243-252.

11 Lamprecht B, Vanfleteren LE, Studnicka M, et al. Sex-related differences in respiratory symptoms: results from the BOLD Study. Eur Respir J 2013; 42: 858-860.

12 Becklake MR, Kauffmann F. Gender differences in airway behaviour over the human life span. Thorax 1999; 54: $1119-1138$

13 Neuman $\AA$, Gunnbjörnsdottir M, Tunsäter A, et al. Dyspnea in relation to symptoms of anxiety and depression: a prospective population study. Respir Med 2006; 100: 1843-1849. 
14 Lindström M, Kotaniemi J, Jönsson E, et al. Smoking, respiratory symptoms, and diseases: a comparative study between northern Sweden and northern Finland: report from the FinEsS study. Chest 2001; 119: 852-861.

15 Ofir D, Laveneziana P, Webb KA, et al. Sex differences in the perceived intensity of breathlessness during exercise with advancing age. J Appl Physiol 2008; 104: 1583-1593.

16 Schaeffer MR, Mendonca CT, Levangie MC, et al. Physiological mechanisms of sex differences in exertional dyspnoea: role of neural respiratory motor drive. Exp Physiol 2014; 99: 427-441.

17 Guenette JA, Jensen D, Webb KA, et al. Sex differences in exertional dyspnea in patients with mild COPD: physiological mechanisms. Respir Physiol Neurobiol 2011; 177: 218-227.

18 European Community Respiratory Health Survey II Steering Committee. The European Community Respiratory Health Survey II. Eur Respir J 2002; 20: 1071-1079.

19 The European Community Respiratory Health Study. www.ecrhs.org Date last accessed: July 2, 2015.

20 Brooks SM. Surveillance for respiratory hazards. ATS News 1982; 8: 12-16.

21 Miller MR, Hankinson J, Brusasco V, et al. Standardisation of spirometry. Eur Respir J 2005; 26: 319-338.

22 Quanjer PH, Stanojevic S, Cole TJ, et al. Multi-ethnic reference values for spirometry for the 3-95-yr age range: the global lung function 2012 equations. Eur Respir J 2012; 40: 1324-1343.

23 McKelvey R, Zavoina W. A statistical model for the analysis of ordinal level dependent variables. J Math Sociol 1975; 4: 103-120.

24 Textor J, Hardt J, Knüppel S. DAGitty: a graphical tool for analyzing causal diagrams. Epidemiology 2011; 22: 745.

25 Greenland S, Pearl J, Robins JM. Causal diagrams for epidemiologic research. Epidemiology 1999; 10: 37-48.

26 Williams RL. A note on robust variance estimation for cluster-correlated data. Biometrics 2000; 56: 645-646.

27 Cory JM, Schaeffer MR, Wilkie SS, et al. Sex differences in the intensity and qualitative dimensions of exertional dyspnea in physically active young adults. J Appl Physiol 2015; 119: 998-1006.

28 Sheel AW, Guenette JA, Yuan R, et al. Evidence for dysanapsis using computed tomographic imaging of the airways in older ex-smokers. J Appl Physiol 2009; 107: 1622-1628.

29 Mead J. Dysanapsis in normal lungs assessed by the relationship between maximal flow, static recoil, and vital capacity. Am Rev Respir Dis 1980; 121: 339-342.

30 Sheel AW, Guenette JA. Mechanics of breathing during exercise in men and women: sex versus body size differences? Exerc Sport Sci Rev 2008; 36: 128-134.

31 Jolley CJ, Moxham J. Dyspnea intensity: a patient-reported measure of respiratory drive and disease severity. Am J Respir Crit Care Med 2016; 193: 236-238.

32 Guenette JA, Witt JD, McKenzie DC, et al. Respiratory mechanics during exercise in endurance-trained men and women. J Physiol 2007; 581: 1309-1322.

33 Global Initiative for Chronic Obstructive Lung Disease (GOLD). Global Strategy for the Diagnosis, Management and Prevention of COPD, 2017. http://goldcopd.org/gold-2017-global-strategy-diagnosis-management-preventioncopd Date last accessed: February 16, 2017.

34 Johannessen A, Verlato G, Benediktsdottir B, et al. Longterm follow-up in European respiratory health studies patterns and implications. BMC Pulm Med 2014; 14: 63.

35 Parshall MB, Schwartzstein RM, Adams L, et al. An official American Thoracic Society statement: update on the mechanisms, assessment, and management of dyspnea. Am J Respir Crit Care Med 2012; 185: 435-452.

36 Hajiro T, Nishimura K, Tsukino M, et al. Analysis of clinical methods used to evaluate dyspnea in patients with chronic obstructive pulmonary disease. Am J Respir Crit Care Med 1998; 158: 1185-1189.

37 Dales RE, Spitzer WO, Schechter MT, et al. The influence of psychological status on respiratory symptom reporting. Am Rev Respir Dis 1989; 139: 1459-1463.

38 Camp PG, Goring SM. Gender and the diagnosis, management, and surveillance of chronic obstructive pulmonary disease. Proc Am Thorac Soc 2007; 4: 686-691.

39 Camp PG, O'Donnell DE, Postma DS. Chronic obstructive pulmonary disease in men and women: myths and reality. Proc Am Thorac Soc 2009; 6: 535-538. 